\title{
Severe retinopathy of prematurity and its association with different rates of survival in infants of less than $1251 \mathrm{~g}$ birth weight
}

\author{
J Vyas, D Field, E S Draper, G Woodruff, A R Fielder, J Thompson, N J Shaw,
} D Clark, R Gregson, J Burke, G Durbin

Departments of Child Health, Epidemiology and Ophthalmology, University of Leicester, Leicester, UK

J Vyas

D Field

E S Draper

$G$ Woodruff

J Thompson

Imperial College School of Medicine, London

A R Fielder

Liverpool Women's Hospital, Liverpool, UK

N J Shaw

D Clark

Queens Medical Centre, Nottingham, UK

R Gregson

Central Sheffield University Hospitals NHS Trust, Sheffield, UK

J Burke

Birmingham Maternity Hospital, Birmingham, UK G Durbin

Correspondence to: Professor D Field, Department of Child Health, Robert Kilpatrick Clinical Sciences Building, University of Leicester, Leicester LE2 7LX, UK

Accepted 24 September 1999

\begin{abstract}
Background-There is controversy over whether improved survival of preterm infants has resulted in a higher incidence of severe (grade 3 or greater) retinopathy of prematurity (ROP).

Aim-To compare survival rates and rates of $\geqslant$ stage 3 ROP-that is, with a high risk of sequelae-in preterm infants in five English cities where, anecdotally, the incidence of ROP is reported to show considerable variation.

Methods-All infants of birth weight $<1500 \mathrm{~g}$ and or gestational age $<32$ weeks, born in 1994 in one of the cities or transferred in within $\mathbf{4 8}$ hours, were studied. The populations were adjusted for case mix variation using CRIB (clinical risk index for babies, a disease severity scoring system). The incidence of severe ROP, the actual death rate, and that adjusted for disease severity were determined.

Results-The rate of severe ROP per 1000 births was higher in city 1 than in all the other cities. This increase in comparison with city 2 and city 4 was significant (city 1,167 (95\% confidence interval (CI) 96 to 260); city 2, 24 (6 to 59); city 4, 16 (1 to 84)). A significant difference was not seen between city 1 and cities 3 (23 (1 to 120)) and 5 (74 (21 to 79$))$. The relative risk of developing severe ROP in city 1 compared with all the other cities was 5.5 (2.5 to 11.9). The actual death rate per 1000 births in city 1 was significantly lower than that predicted by modelling death against CRIB score (city 1: actual 270; predicted $385(95 \%$ CI 339 to 431$)$ ). In contrast, the other cities had actual death rates as predicted, or worse than predicted, by CRIB. Interpretation-A significantly higher incidence of severe ROP was identified in one of the five cities studied. Variation in survival rates among high risk infants may explain this observation.
\end{abstract}

(Arch Dis Child Fetal Neonatal Ed 2000;82:F145-F149)

Keywords: eye; retinopathy of prematurity; very preterm infants; survival rates; oxygen treatment

Retinopathy of prematurity (ROP) is a disease of the developing retinal blood vessels. It was originally reported in $1942,{ }^{1}$ and nine years later an association with supplemental oxygen treatment was suggested. ${ }^{2}$ The link to oxygen treatment was investigated experimentally by
Ashton $^{3}$ and Patz ${ }^{4}$ and in a number of clinical studies. ${ }^{5}$ This work led to oxygen restriction, and the incidence of ROP fell, although the death rate of preterm infants rose. ${ }^{6}$ From the late 1970 s, as neonatal intensive care became established widely in the developed world, the incidence of ROP increased again..$^{7-9}$ This observation has been the subject of much debate, with studies trying to interpret changes in the incidence of ROP against the following background.

(1) The mean gestation of infants requiring intensive care for respiratory distress syndrome fell because (a) the number of premature infants $\leqslant 32$ weeks' gestation admitted to intensive care units rose considerably and (b) respiratory problems in premature infants of $>32$ weeks' gestation became less common. ${ }^{10}$

(2) Units varied in their approach to the most immature babies, with some classifying a high proportion as livebirths and considering them for intensive care, whereas others treated most of these babies as stillbirths. ${ }^{11}$

(3) Survival of premature infants improved. ${ }^{12}$

Clearly individual study populations used to investigate the incidence of ROP have varied in the rate and extent to which they have been affected by these changes. As a result, conclusions on the important influences on current rates of ROP have varied, with some studies suggesting that improved survival explains the increased incidence of ROP and ROP induced blindness, ${ }^{78}$ whereas others take the opposite view. ${ }^{13-15}$ Central to the discussion are the questions of whether infants develop ROP because of care that is deficient in some way, and whether, with optimal support, ROP is always avoidable? In contrast, it is certainly plausible that high rates of ROP may be a consequence of excellent care which allows the least mature, most physiologically unstable, infants to survive and develop ROP.

Anecdotal reports suggest that the incidence of severe $\mathrm{ROP}^{16}$ varies between centres that provide routine screening for ROP in the UK. We wished to assess whether this apparent variation was real and whether, if present, it was the result of different rates of survival.

\section{Methods}

The study was conducted retrospectively. Data were collected from 11 neonatal intensive care units in five cities in England (Birmingham, Leicester, Liverpool, Nottingham, Sheffield). Each city was covered by a single screening 
service for ROP. Infants included in the study were all livebirths born in 1994 in one of the hospitals collaborating (or were transferred in within 48 hours of age), and who were within the British Association of Perinatal Medicine/ Royal College of Ophthalmologists ROP screening criteria (birth weight $<1500 \mathrm{~g}$ and/or gestational age $<32$ weeks). ${ }^{17}$

The data collected were birth weight, gestational age, development of stage 3 ROP or greater, and clinical risk index for babies (CRIB) score. CRIB is a disease severity scoring system for preterm infants, and can be used to adjust for case mix in different populations. ${ }^{18}$

Eye examinations were performed by senior members of the local ophthalmology team who had a special interest in screening for ROP. Findings were recorded using the internationally recognised classification. ${ }^{16}$ The examinations were performed by binocular indirect fundoscopy with or without a scleral indent by the unit's usual technique. For each infant who received an eye examination, the maximum stage of ROP reached, the presence or absence of "plus" disease, ${ }^{19}$ and the need for treatment was recorded. Death before the first eye check was recorded. Infants were regarded as survivors if they lived beyond the time recommended for a first eye check. Death after this time was not included in the death rate analysis.

The ophthalmologists in the study agreed that, to limit the effect of interobserver error inherent in any clinical scoring system, data on

Table 1 Number of eligible infants, the number surviving to the first eye check, crude survival rate, and the number of cases of $\geqslant$ stage 3 retinopathy of prematurity (ROP) in each city

\begin{tabular}{lcclc}
\hline City & No of infants & No of survivors & $\begin{array}{l}\text { Crude survival rate per } \\
\text { 1000 births } \leqslant 1250 \mathrm{~g}\end{array}$ & $\begin{array}{l}\text { No of cases of } \\
\text { stage 3 ROP }\end{array}$ \\
\hline 1 & 122 & 90 & 737 & 15 \\
2 & 235 & 169 & 719 & 4 \\
3 & 65 & 44 & 677 & 1 \\
4 & 103 & 64 & 621 & 1 \\
5 & 95 & 54 & 568 & 4 \\
Total & 620 & 421 & 679 & 25 \\
\hline
\end{tabular}

Table 2 Distribution of high risk characteristics (infants $<26$ weeks' gestation, infants $<751 \mathrm{~g}$ birth weight, and infants with CRIB score > 10) between the five cities

\begin{tabular}{|c|c|c|c|}
\hline \multirow[b]{2}{*}{ City } & \multicolumn{3}{|l|}{ Survival in infants } \\
\hline & $\begin{array}{l}<26 \text { weeks' gestation } \\
(\%(95 \% C I))\end{array}$ & $\begin{array}{l}<751 \text { g birth weight } \\
(\%(95 \% \text { CI }))\end{array}$ & $\begin{array}{l}\text { With } C R I B>10 \\
(\%(95 \% C I))\end{array}$ \\
\hline 1 & $47.5(31.5-63.9) \mathrm{n}=19$ & $41.2(24.7-59.3) \mathrm{n}=14$ & $25.2(17.6-34.2) \mathrm{n}=29$ \\
\hline 2 & $37.5(24.0-52.7) \mathrm{n}=18$ & $41.8(28.7-55.9) \mathrm{n}=23$ & $20.5(13.6-29.0) \mathrm{n}=24$ \\
\hline 3 & $7.7(0.2-36.0) \mathrm{n}=1$ & $20.0(2.5-55.6) \mathrm{n}=2$ & $15.6(7.8-26.9) \mathrm{n}=10$ \\
\hline 4 & $33.3(15.6-55.3) \mathrm{n}=8$ & $42.1(20.3-66.5) n=8$ & $19.0(11.8-28.1) \mathrm{n}=19$ \\
\hline 5 & $30.8(14.3-51.8) \mathrm{n}=8$ & $23.1(9.0-43.7) \mathrm{n}=6$ & $16.1(9.3-25.2) \mathrm{n}=15$ \\
\hline
\end{tabular}

$\mathrm{n}$, number of survivors.

Table 3 Distribution of cases of $\geqslant$ stage 3 retinopathy of prematurity (ROP) by birth weight and city

\begin{tabular}{lccc}
\hline & $500-749 g$ & $750-999 g$ & $1000-1250 g$ \\
\hline City 1 & 5 & 9 & 1 \\
City 2 & 2 & 1 & 1 \\
City 3 & 0 & 1 & 0 \\
City 4 & 1 & 0 & 0 \\
City 5 & 1 & 3 & 0 \\
Total ₹ stage 3 ROP & 9 & 14 & 2 \\
Total babies screened & 48 & 149 & 224 \\
\% of screened babies with severe ROP & 18.8 & 9.4 & 0.9 \\
95\% CI & 9.0 to 32.6 & 5.2 to 15.2 & 0.1 to 3.2 \\
\hline
\end{tabular}

the presence of ROP stage 3 and above would be most reliable. Less severe stages of ROP are not associated with a significant risk of progression to visual impairment, whereas infants who reach $\geqslant$ stage 3 ROP have a very high risk of future visual problems such as vision impairment, strabismus, and myopia. ${ }^{19}$ Thus it was of clinical importance to determine the incidence of this degree of ROP.

Infants who were transferred back to another hospital not in the study were traced to that hospital and the baby's ROP staging was determined from the notes.

Statistical analysis of the data was carried out using SAS software. ${ }^{20}$ For the incidence of severe ROP, 95\% confidence intervals (CI) were calculated using exact methods for the binomial distribution. Logistic regression models were used to calculate the predicted death rate in each city, with adjustment for morbidity using the expected rates of incidence by CRIB score from the combined population, individual weeks of gestation, and a factor to adjust for the interaction between gestation and CRIB.

\section{Results}

The results from the five cities are presented in anonymous form.

Data were retrieved on 1098 infants. No child of birth weight $1251 \mathrm{~g}$ or more had $\geqslant$ stage 3 ROP. The population studied was therefore limited to infants of less than $1251 \mathrm{~g}$ birth weight. This resulted in a secondary cohort of 620 infants, of whom $421(67.9 \%)$ survived to the first eye check. Table 1 shows the number of live born infants and survivors in this latter cohort. The results of an eye examination were unable to be traced for 22 (3.5\%) infants out of this group of 620 following transfer from one of the study hospitals. None of these infants later presented to the local ophthalmology teams with visual problems, and it was assumed that they did not have $\geqslant$ stage 3 ROP. These missing data were spread throughout the five cities. CRIB data were unable to be obtained for 131/620 (21.1\%) infants, $118(90 \%)$ of whom were from city 2 . None of these infants had $\geqslant$ stage 3 ROP.

Table 2 illustrates a number of risk factors present in the different populations. No differences were seen between the cities when comparing unadjusted rates of survival of infants $<26$ weeks' gestation or $<751 \mathrm{~g}$ birth weight. The percentage of infants entering the study with a poor CRIB score (> 10) similarly showed no difference. It is interesting to note the low number of infants < 26 weeks' gestation and $<751 \mathrm{~g}$ birth weight in city 3 . This finding was not significant.

The incidence of $\geqslant$ stage 3 ROP per 1000 infants surviving in city 1 was 167 (95\% CI 96 to 260). This was higher than in the other four cities. The excess of severe ROP reached statistical significance in comparisons with city 2 (24 (6 to 59$)$ ) and city 4 (16 (0 to 84$))$. In city 3 , incidence of $\geqslant$ stage 3 ROP was 23 ( 1 to 120 ), and in city 5 the incidence was 74 (21 to 179 ). The relative risk of $\geqslant$ stage 3 ROP in city 1 compared with the other four cities was 5.5 
Table 4 Distribution of cases of $\geqslant$ stage 3 retinopathy of prematurity (ROP) by gestation and city

\begin{tabular}{|c|c|c|c|c|c|c|c|}
\hline & 22 weeks & 23 weeks & 24 weeks & 25 weeks & 26 weeks & 27 weeks & 28 weeks \\
\hline City 1 & 1 & 1 & 5 & 3 & 3 & 1 & 1 \\
\hline City 2 & 0 & 0 & 0 & 2 & 0 & 1 & 1 \\
\hline City 3 & 0 & 0 & 0 & 0 & 0 & 1 & 0 \\
\hline City 4 & 0 & 1 & 0 & 0 & 0 & 0 & 0 \\
\hline City 5 & 0 & 0 & 0 & 3 & 1 & 0 & 0 \\
\hline \multicolumn{8}{|l|}{ Total no with ROP stage 3} \\
\hline or greater & 1 & 2 & 5 & 8 & 4 & 3 & 2 \\
\hline Total no of babies screened & 1 & 4 & 15 & 34 & 41 & 86 & 76 \\
\hline$\%$ with severe ROP & 100.0 & 50.0 & 33.3 & 23.5 & 9.8 & 3.5 & 2.6 \\
\hline $95 \% \mathrm{CI}$ & 2.5 to 100.0 & 6.8 to 93.2 & 11.8 to 61.6 & 10.8 to 41.2 & 2.7 to 23.1 & 0.7 to 9.9 & 0.3 to 9.2 \\
\hline
\end{tabular}

(2.5 to 11.9). We felt that this post hoc comparison was justified because the anecdotal reports that led to this study related to a high incidence of ROP in city 1.

Tables 3 and 4 show the distribution of cases by birth weight and gestation respectively. The small numbers in each city show no pattern, but the aggregated data showing the proportion of infants affected show a clear link to birth weight and gestation.

The logistic regression model (CRIB) disclosed that the actual death rate for city 1 (270/ 1000 live births $\leqslant 1250 \mathrm{~g}$ ) was significantly lower than that predicted by the model (385/1000 live births $\leqslant 1250 \mathrm{~g}(95 \%$ CI 339 to 431)). The actual death rates for cities 2,3 , and 4 were within the confidence intervals of the rate predicted by the CRIB score (city 2, $316 / 1000$ live births $\leqslant 1250 \mathrm{~g} v$ CRIB estimate 334 (95\% CI 289 to 382); city 3, 328/1000 live births $\leqslant 1250 \mathrm{~g} v$ CRIB estimate 280 (95\% CI 193 to 368); city 4, 370/1000 live births $\leqslant 1250 \mathrm{~g} v$ CRIB estimate 327 (95\% CI 280 to 376)). The actual death rate for city 5 was significantly higher than that predicted by the model (430/1000 live births $\leqslant 1250 \mathrm{~g} v$ CRIB estimate 344 (95\% CI 266 to 423)).

Within CRIB, gestation has only a small weighting. As the risk of ROP is known to be closely associated with low gestation, it seemed appropriate to investigate whether variation in the distribution of gestation between the centres was responsible for the observed differences. Therefore a "new model" was derived to predict mortality using week of gestation as an additional variable to adjust the CRIB prediction. Although the overall "fit" of the model was improved, the pattern seen with CRIB alone (with fewer than expected deaths in city 1 and excess deaths in city 5) remained (city 1 , $270 / 1000$ live births $\leqslant 1250 \mathrm{~g} v$ new model estimate 391 ( $95 \%$ CI 323 to 456); city 5, 430/ 1000 live births $\leqslant 1250 \mathrm{~g} v$ new model estimate 344 (95\% CI 280 to 409)).

\section{Discussion}

The results presented show a significant variation in the incidence of $\geqslant$ stage 3 ROP. This was highest in city 1 where the finding was accompanied by a death rate that was significantly lower than that predicted by the CRIB score. Cities 2, 3, and 4 had actual death rates within the range predicted by the CRIB score and an incidence of severe ROP far lower than that of city 1 . These data suggest that improved survival and the development of severe ROP are associated. City 5 has a worse than predicted death rate but an incidence of severe
ROP closest to that of city 1 , albeit not significantly different from any of the cities. The major neonatal unit serving city 5 has a policy of assessing on the neonatal unit and recording as a live birth even the most immature infants born alive. CRIB was not developed to adjust for such an effect and we believe this policy is responsible for the higher than expected mortality.

We did not identify any infant over $1250 \mathrm{~g}$ birth weight with $\geqslant$ stage 3 ROP; however, this does not indicate that current recommendations for screening (all babies $\leqslant 1500 \mathrm{~g}$ ) are too wide. It would not be appropriate to draw such a conclusion from a study that was not designed to investigate incidence in relation to birth weight.

Existing studies in the literature do not present a clear picture of the major influences on the incidence of ROP. Only two have reported conventional incidence studies making point estimates in geographically defined populations. ${ }^{1321}$ The first used admissions to neonatal intensive care units as a denominator, and the second used all deliveries in the relevant birthweight category. It is known that differences in attitude with regard to the "limits of viability" have played an important part in determining access to neonatal intensive care. ${ }^{11}$ Therefore it is impossible to assess the extent to which decisions about viability made by individual hospitals within the two study boundaries resulted in the most immature babies, with the highest potential for developing severe ROP, being either included or excluded.

Differences in attitudes to viability are likely to have been of far greater importance in those studies that compared rates of ROP and or ROP blindness over time ${ }^{7-9}$ and which have drawn different conclusions over whether improved survival does or does not account for observed changes in incidence. Interpretation of these studies is made more difficult by additional factors. Over time, an increasing proportion of immature babies have been offered intensive care, but in addition a greater percentage of more mature babies have avoided the need for such support..$^{10}$ As a result, the populations being compared in these investigations will be fundamentally different over time. Of equal importance in studies that have sometimes compared populations extending over 30 years are the major changes in the nature of intensive life support. Given these dramatic changes, it is possible that particular 
treatments exerted a specific influence on the incidence of ROP, independently of survival per se.

It has also been suggested that ROP is more common when preterm infants receive their care away from major centres. ${ }^{13}{ }^{14}$ This concept may similarly not be sound. Population based studies in one region of the UK indicate that, currently, infants $\leqslant 28$ weeks' gestation transferred postnatally have a better outcome (corrected for disease severity) than similar infants whose care is entirely within one unit, small or large. ${ }^{22}$ This selection of infants may have an important influence on observed rates of ROP when transferred infants are analysed as part of the whole group cared for in the major centre(s) within a particular study.

In an attempt to deal with these various confounding issues, our study was based on the same 12 month period in all the units, and at a time when modern neonatal intensive care practice was well established and in general terms standardised in each of the participating centres. In addition, the comparisons were standardised in terms of survival using CRIB to adjust for case mix.

However, there are shortcomings within the approach we have taken. The study is limited by the small numbers of cases of severe ROP in cities $2,3,4$, and 5 (10 in total) and by the fact that data are from one year only. We have used the CRIB score as a measure of initial disease severity and this scoring system was derived from infants who were generally of greater gestational age than infants in this study. We have made the assumption that basic differences in the population, such as levels of deprivation, will be manifest, and corrected for, through the severity of illness. Specific ethnic influences and variation in any genetic propensity to develop ROP have been ignored. ${ }^{21}{ }^{23}{ }^{24} \mathrm{In}$ spite of these caveats, we feel the data show an important association between survival and the incidence of $\geqslant$ stage 3 ROP.

It is our belief that in any one setting it is a complex interplay between the presenting population and both the quantity and quality of intensive care available that determines the measured rate of ROP. Improved understanding of the pathogenesis of ROP supports the importance of cardiorespiratory stability. ${ }^{25} \mathrm{Ob}$ servational studies confirm the association of physiological instability and the incidence of ROP. ${ }^{26}$ Therefore, even where neonatal intensive care facilities are well established, in the most immature infants, who are inherently unstable, the risk of ROP is high and will be manifested if they survive. Poor quality intensive care in such a setting may produce a range of effects depending on whether survival is jeopardised or not. In a situation in which the population is changing, with a more positive attitude being taken with regard to the care of immature infants, one would expect an increase in the incidence of ROP until both the change and the learning curve of the perinatal service is complete. For example, Gilbert et $a l^{27}$ studying blindness from ROP in "middle income countries" in Eastern Europe, Asia, Latin America, and Africa reported that, in those countries with lower infant death rates, ROP accounted for a greater proportion of the cases of severe visual impairment or blindness. The influence of new approaches to treatment, with no obvious direct effect on the eye, is more complex to predict. Higgins et $a l^{28}$ in a single centre study showed a decrease in severe ROP associated with antenatal dexamethasone administration. They did not, however, comment on whether the dexamethasone was associated with a concomitant increase in survival. Previously, the effect of antenatal corticosteroids on ROP was reported as inconclusive. ${ }^{29}$ It is likely that the measured effect of dexamethasone on ROP will reflect the extent to which improved survival alters the study population either directly or through a change in attitude to viability.

There seems to be no doubt that poor care of any newborn infant, for example inappropriate and uncontrolled use of oxygen, can lead to the production of ROP. However, for the most immature infants, with homoeostatic mechanisms that are not fully developed, the aggressive interventions necessary for survival may be sufficient to initiate ROP. Hence excellent care with improved odds for survival may in fact carry with it an increased risk for development of ROP, and it is possible that, with current therapeutic strategies, we cannot always prevent this disease and continue to improve survival. The development of new interventions that will be able to deal with this specific risk has become the new challenge. ${ }^{30}$

We wish to acknowledge the help and support of colleagues in participating centres, in particular D Jones, J Ainsworth, J G Bissenden, L Butler, A K Ewer, R Mupanemunda, and M Watkinson. We are also very grateful for the assistance given to us by the clinical and clerical staff at the collaborating units as well as members of the Trent infant mortality and morbidity studies (TIMMS) team (Martin Perkins, Nicky Spiers, Bradley Manktelow, Mrs B Siddons, Dilys Ainsworth, Gilly Grant, Karen
Lynch, Gill Mellors, Joy Yates). Lens

1 Terry TL. Extreme prematurity and fibroplastic overgrowth of persistent vascular sheath behind each crystalline lens. I. of persistent vascular sheath behind each crystalline le

2 Campbell K. Intensive oxygen therapy as a possible cause of retrolental fibroplasia: a clinical approach. Med $f$ Aust 1951;2:48-50.

3 Ashton N. Oxygen and retinal blood vessels. Transactions of the Ophthalmological Society of the United Kingdom 1980;100:359-62.

4 Patz A. Retrolental fibroplasia (retinopathy of prematurity). Transactions of the Ophthalmological Society of New Zealand 1980;32:49-54

5 Fielder AR. Retinopathy of prematurity: aetiology. Clinical Risk 1997;3:47-51.

6 Cross KW. Cost of preventing retrolental fibroplasia? Lancet 1973;ii:954.

7 Gibson DL, Sheps SB, Uh SH, Schechter MT, McCormick AQ. Retinopathy of prematurity-induced blindness: birth
weight-specific survival and the new epidemic. Pediatrics 1990;86:405-12.

8 Valentine PH, Jackson JC, Kalina RE, Woodrum DE. Increased survival of low birth weight infants: impact on the incidence of retinopathy of prematurity. Pediatrics 1989;84:442-5.

9 Keith CG, Doyle LW. Retinopathy of prematurity in extremely low birth weight infants. Pediatrics 1995;95:425.

10 Field D, Milner AD, Hopkin IE, Madeley RJ. Changing overall workload in neonatal units. BMf 1985;290:153942

11 Fenton AC, Field DJ. Attitudes to viability of preterm infants and their effect on figures for perinatal mortality. BMF 1990;300:434-6.

12 Botting B, ed. The health of our children. Decennial supplement. Office of Population Censuses and Surveys Series DS no 11. London: HMSO, 1995.

13 Darlow BA, Horwood LJ, Clemett RS. Retinopathy of prematurity: risk factors in a prospective population-based maturity: risk factors in a prospective population
study. Paediatr Perinat Epidemiol 1992;62:62-80.

14 Schaffer DB, Palmer EA, Plotsky DF, et al on behalf of the cryotherapy for retinopathy of prematurity cooperative 
group. Prognostic factors in the natural course of retinopathy of prematurity. Ophthalmology 1993;100:230re

15 Emsley HCA, Wardle SP, Sims DG, Chiswick ML, D’Souza SW. Increased survival and deteriorating developmental outcome in 23 to 25 week old gestation infants. 1990-4 compared with 1984-9. Arch Dis Child Fetal Neonatal Ed 1998;78:F99-104.

16 An international classification of retinopathy of prematurity. Arch Ophthalmol 1984;102:1130.

17 Report of a Joint Working Party. Retinopathy of prematurity: guidelines for screening and treatment. London: Royal College of Ophthalmologists and British Association of Perinatal Medicine, 1995. Early Hum Dev 1996;46:239-58.

18 The International Neonatal Network. The CRIB (clinical risk index for babies) score: a tool for assessing initial neonatal risk and comparing performance of neonatal natal risk and comparing performance
intensive care units. Lancet 1993;342:193-8.

19 Cryotherapy for retinopathy of prematurity cooperative group multicentre trial of cryotherapy for retinopathy of group multicentre trial of cryotherapy for retinopathy of
prematurity: preliminary results. Arch Ophthalmol prematurity: pretir

20 SAS procedures guide, version 6. 3rd ed. Cary, NC: SAS Institute Inc, 1990

$21 \mathrm{Ng}$ YN, Fielder AR, Shaw DE, Levene MI. Epidemiology of retinopathy of prematurity. Lancet 1988;ii:1235-8.

22 Field D, Draper ES. Survival and place of delivery following preterm birth: 1994-1996. Arch Dis Child Fetal Neonatal Ed 1999;80:F111-14
23 Saunders RA, Donahue ML, Christmann LM, et al. Racial variation in retinopathy of prematurity. Arch Ophthalmol 7; 115:604-8.

24 Shastry BS, Pendergrast SD, Hatzer MK, Liu X, Trese MT. Identification of missense mutations in the Norrie disease gene associated with advanced retinopathy of prematurity. Arch Ophthalmol 1997;115:651-5.

25 Alon T, Hemo I, Itin A, Pe'er J, Stone J, Keshet E. Vascular endothelial growth factor acts as a survival factor for newly formed retinal vessels and has implications for retinopathy of prematurity. Nat Med 1995;1:1024-8.

26 Cunningham S, Fleck BW, Elton RA, Mcintosh N. Transcutaneous oxygen levels in retinopathy of prematuTranscutaneous oxygen levels
rity. Lancet 1995;346:1464-5.

27 Gilbert C, Rahi J, Eckstein M, O'Sullivan J, Foster A. Retinopathy of prematurity in middle income countries. Lancet 1997;350:12-14.

28 Higgins RD, Mendelsohn AL, DeFeo MJ, Ucsel R, Hendricks-Munoz KD. Antenatal dexamethasone and decreased severity of retinopathy of prematurity. Arch Ophthalmol 1998;116:601-5.

29 Moise AA, Weardon ME, Kozinetz CA, Gest AL, Welty SE, Hansen TN. Antenatal steroids are associated with less need for blood pressure support in extremely premature infants. Pediatrics 1995;95:845-50.

30 Phelps DL, Lakatos L, Watts JL. D-Penicillamine for preventing retinopathy of prematurity in preterm infants. The Cochrane Library, Issue 2. Oxford: Update Software, 1999. 